\title{
Argamassas geopoliméricas à base de cinzas volantes álcali-ativadas contendo areia de fundição
}

\section{(Geopolymeric mortars based on alkali-activated fly ash containing sand casting)}

\author{
A. S. de Vargas, E. L. Schneider, G. Schmitz, P. M. De Aquim \\ Universidade Feevale, ICET, Novo Hamburgo, RS, Brasil 93352-000 \\ alexandrev@feevale.br,eduardoluis@feevale.br,gabrielsch2@terra.com.br,patrice@feevale.br
}

\begin{abstract}
Resumo
Os processos fundição compreendem as etapas de fusão e vazamento de metais em moldes, obtendo a requerida forma sólida. Dentre os materiais dos moldes empregados, a fundição com molde em areia é o processo mais comum devido ao menor custo em relação aos demais. A indústria de fundição utiliza areia misturada a resinas orgânicas, inorgânicas e mistas para composição dos machos e moldes, nos quais o metal é vazado para formar diversas peças. Esse processo gera uma grande quantidade de areia residual, denominada areia de fundição (AF), que tem que ser descartada em aterros especiais. Neste sentido, este trabalho tem como objetivo analisar a viabilidade técnica do uso da $\mathrm{AF}$ em substituição à areia de construção convencional em argamassas álcali-ativadas. Essas argamassas foram preparadas a partir da álcali-ativação de cinza volante e metacaulim, com quatro teores distintos de substituição de AF: $25 \%, 50 \%, 75 \%$ e $100 \%$. Após 7 e 28 dias de cura à temperatura ambiente as amostras foram submetidas a ensaios de resistência à compressão. A caracterização microestrutural foi realizada na idade de 28 dias com o auxílio do difratômetro de raios X e do espectômetro de infravermelho . Nos diferentes traços foi percebida a necessidade de aumento de água na composição da argamassa à medida que a proporção de $\mathrm{AF}$ foi aumentada. Este aumento de água influenciou na queda de resistência à compressão das argamassas, na medida em que o teor de substituição de AF foi aumentado.
\end{abstract}

Palavra-chave: areia de fundição, reaproveitamento de resíduos, argamassas álcali-ativadas.

\begin{abstract}
Casting processes comprise the steps of melting and pouring metal into molds, obtaining the required solid shape. Among the materials employed in molds, sand casting mold is the most common process due to lower cost. The casting industry uses sand mixed with organic, inorganic and mixed resins for the production of the cores and molds, in which the metal is cast to form several parts. This process generates a large amount of residual sand, called sand of casting, which has to be discarded in special landfills. Thus, this study aims to investigate the feasibility of using sand of casting to replace conventional sand of building in alkali-activated mortars. These mortars were prepared from alkali-activated fly ash, and metakaolin with four different sand of casting substitution levels: $25 \%, 50 \%, 75 \%$ and 100\%. After 7 and 28 days of curing at room temperature the samples were tested for compressive strength. Microstructural characterization was performed at the age of 28 days with the help of X-ray diffractometer and infrared spectrometer. In the different traits were perceived a need to increase the water of the mortar composition as the proportion of sand of casting was increased. This increase in water influenced the decrease of compression strength of mortar to the extent that the level of replacement of sand of casting was increased.
\end{abstract}

Keywords: sand casting, wastes reuse, alkali-activated mortars.

\section{INTRODUÇÃ̃O}

Os processos de fundição permitem a fabricação de peças de diversas geometrias permitindo a obtenção de formas permanentes, com propriedades mecânicas e que podem suportar as mais variadas condições de serviço. Dentre estes processos, os mais comumente utilizados são os por gravidade, sob pressão, por centrifugação e precisão (também conhecido por cera perdida). Os critérios considerados para a escolha do processo são as quantidades de peças a serem produzidas, a geometria das peças, característica dimensional, tolerâncias requeridas, grau de complexidade, especificação do metal, ferramental e o acabamento superficial $[1,2]$.

O processo de fundição com molde em areia é considerado o mais tradicional nas fundições e a confecção do molde é uma etapa importante do processo, pois é o que permite a distinção entre os diversos processos de fundição [1]. O processo de fundição em areia passa por etapas, desde a confecção do modelo da peça, a confecção do molde, a confecção do macho, massalotes, respiros e canais de vazamento, fechamento do molde, fusão, vazamento, corte de canais e massalotes, rebarbação e limpeza e, finalmente, inspeção final e recuperação. Neste processo é realizada a compactação de uma mistura refratária, denominada areia de fundição, que é 
depositada no modelo ou sobre a caixa de moldar. Realiza-se a compactação da areia ao encontro do modelo da peça que se pretende obter [3]. No processo de fundição em molde de areia os moldes e machos são construídos de uma mistura de areia base com resinas orgânicas (tais como resinas furânicas, fenólicas, uretânicas), (1 a 2\%), bentonita (1\%), pó de carvão (2\%), amido de milho (1\%), inorgânicas (como o silicato de sódio e o cimento Portland) e mistas (como as resinas fenólicas alcalinas) [4]. Após o processo de vazamento, a maior parte da areia usada é reutilizada diretamente na produção de peças fundidas, sem qualquer tratamento prévio. Entretanto, há uma parcela de areia não utilizada no vazamento ou não retornada diretamente ao processo que deve sofrer tratamentos para a regeneração ou a disposição final. A areia recirculada (Fig. 1) apresenta um acúmulo de materiais residuais, como restos de resinas curadas ou de argilas, carvões e outros aditivos termicamente degradados no processo de vazamento [5].

Neste sentido, este trabalho tem como objetivo avaliar a resistência à compressão e as características mineralógicas de

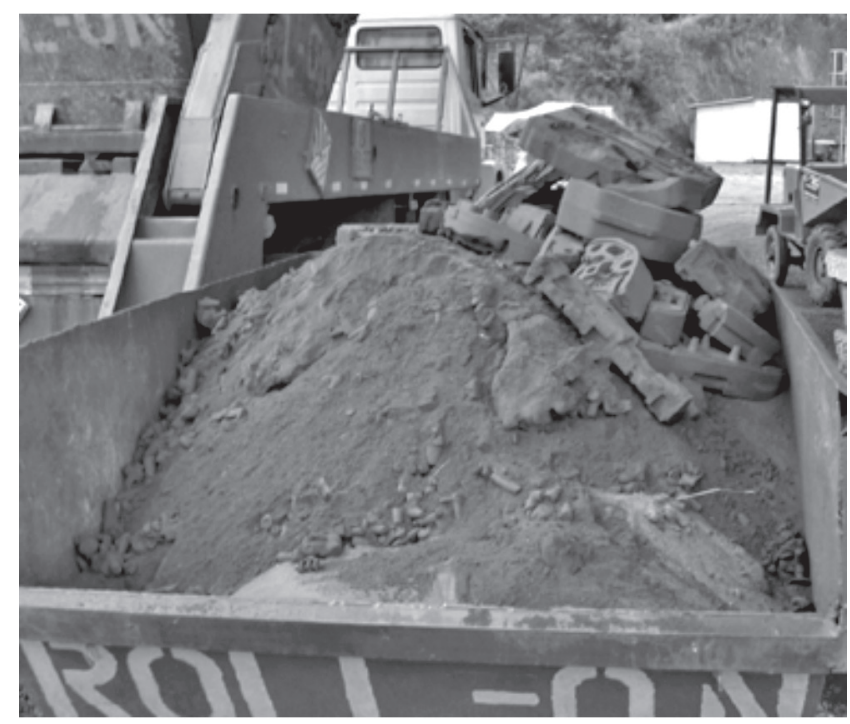

Figura 1: Resíduo de moldes de areia de fundição.

[Figure 1: Wastes of sand casting molds.]

argamassas álcali-ativadas contendo distintos teores de $\mathrm{AF}$, em substituição à areia convencional de construção. Os cimentos álcali-ativados, muitas vezes denominados na literatura como cimentos geopoliméricos, são obtidos a partir de materiais compostos predominantemente por aluminossilicatos amorfos (cinza volante, metacaulim, escórias de alto forno, entre outros) submetidos a um ambiente altamente alcalino, conseguido através de base alcalinas, sendo as mais utilizadas:
$\mathrm{NaOH}, \mathrm{KOH}, \mathrm{Ca}(\mathrm{OH})_{2}$ e $\mathrm{Na}_{2} \mathrm{SiO}_{3}$ [6-9]. A geopolimerização, também chamada de ativação alcalina, é um processo químico que permite transformar estruturas vítreas (parcialmente ou totalmente amorfo e/ou metaestável) em um compósito bem compactado e cimentante [9]. O atrativo é a possibilidade do reaproveitamento de resíduos ou subprodutos, para a produção de cimentos especiais, de menor impacto ambiental para a sua produção, quando comparado a processo de produção do cimento Portland. Nas devidas proporções entre os aluminossilicatos e ativadores poderá ser conseguida uma policondensação eficiente dos aluminossilicatos, obtendo desta forma um material sólido com propriedades mecânicas interessantes para a construção civil.

\section{MATERIAIS E MÉTODOS}

A cinza volante $(\mathrm{CV})$ e a areia de fundição $(\mathrm{AF})$ foram geradas em uma usina termelétrica e em uma indústria de fundição, respectivamente, ambas localizadas no estado do Rio Grande do Sul (Brasil). O metacaulim (MK) utilizado foi do tipo comercial. Na Fig. 2 é apresentado o difratograma de raios $\mathrm{X}$ da areia de fundição (AF), do metacaulim (MK) e da cinza volante $(\mathrm{CV})$.

Como pode ser observado no difratograma apresentado na Fig. 2, o quartzo $\left(\mathrm{SiO}_{2}\right)$ é o composto cristalino predominante das três amostras analisadas. A partir dos dados da Tabela I, constata-se que a CV (classe F, segundo a ASTM C 612803(7)) [10] e o MK utilizados possuem baixos teores de cálcio

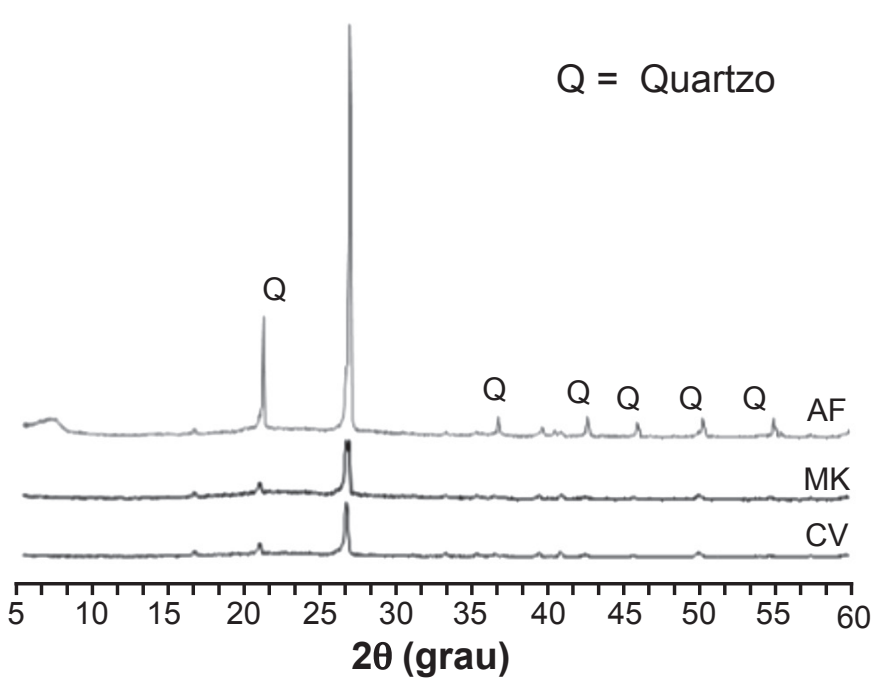

Figura 2: Difratogramas de raios $\mathrm{X}$ da areia de fundição (AF), do metacaulim (MK) e da cinza volante (CV).

[Figure 2: X-ray diffraction patterns of foundry sand $(A F)$ of metakaolin (MK) and fly ash (CV).]

Tabela I - Composição química da cinza volante e metacaulim (\% em peso).

[Table I - Chemical composition of fly ash and metakaolin (wt.\%).]

\begin{tabular}{lccccccccc}
\hline Material & $\mathrm{SiO}_{2}$ & $\mathrm{Al}_{2} \mathrm{O}_{3}$ & $\mathrm{CaO}$ & $\mathrm{Fe}_{2} \mathrm{O}_{3}$ & $\mathrm{Na}_{2} \mathrm{O}$ & $\mathrm{TiO}_{2}$ & $\mathrm{MgO}$ & $\mathrm{K}_{2} \mathrm{O}$ & $\mathrm{SO}_{4}$ \\
\hline $\mathrm{CV}$ & 70,79 & 14,65 & 2,65 & 5,90 & 0,132 & 2,195 & 0,261 & 2,35 & 0,496 \\
$\mathrm{MK}$ & 58,39 & 38,2 & 0,11 & 1,7 & 0,27 & 1,24 & 0,24 & 0,18 & 0,17 \\
\hline
\end{tabular}


e são constituídos preponderantemente por $\mathrm{SiO}_{2}$ e $\mathrm{Al}_{2} \mathrm{O}_{3}$. Materiais constituídos por aluminossilicatos apresentam excelente potencial na tecnologia de álcali-ativação para a obtenção de geopolímeros.

\section{Ativadores alcalinos}

Os ativadores alcalinos empregados foram hidróxido de sódio, $\mathrm{NaOH}$, comercial com pureza $98 \%$, e silicato de sódio comercial, $\mathrm{Na}_{2} \mathrm{SiO}_{3}\left(32,55 \% \mathrm{SiO}_{2}\right.$ e $\left.15,10 \% \mathrm{Na}_{2} \mathrm{O}\right)$.

\section{Metodologia}

Foram preparadas argamassas à base de cinzas volantes (CV) e metacaulim (MK) álcali-ativadas, a partir de solução combinada de $\mathrm{NaOH}$ e $\mathrm{Na}_{2} \mathrm{SiO}_{3}$. A argamassa referência foi preparada contendo $70 \%$ de MK e $30 \%$ de CV, álcali-ativadas com solução contendo $50 \% \mathrm{NaOH}$ e $50 \% \mathrm{Na}_{2} \mathrm{SiO}_{3}$. A partir desta argamassa foram adotados teores de $\mathrm{AF}$, em substituição à areia de construção, de 25\%,50\%,75\% e 100\% (em massa). Além disso, foram utilizadas quatro frações de areia - material retido entre as peneiras da série normal 2,4-1,2; 1,2-0,6; $0,6-0,30 ; 0,30-0,15 \mathrm{~mm}$-, tanto para a areia de construção quanto para a areia de fundição, representando cada uma $25 \%$ do agregado miúdo, conforme estabelece a NBR 7215 [11]. O preenchimento e adensamento das argamassas nos moldes metálicos $(\phi 5 \mathrm{~cm}$ e altura $10 \mathrm{~cm})$ para o preparo dos corpos-de-prova (CP) foram realizados em quatro camadas, sendo necessárias em cada camada a aplicação de 30 golpes, conforme estabelece a NBR 7215- 96. Após, os CPs foram curados à temperatura ambiente, até as idades de ensaios de resistência à compressão, 7 e 28 dias. Para cada idade, quatro CPs foram submetidos aos ensaios de resistência e os resultados apresentados são o valor médio da resistência para cada traço. A partir dos CPs rompidos, na idade de 28 dias, foram preparadas amostras para as análises de DRX e de FTIR.

\section{Consistência}

Para análise de consistência das argamassas geopoliméricas no estado fresco, foi utilizada a mesa de consistência. Esse ensaio é realizado enchendo-se um molde cônico, disposto sobre a mesa, com argamassa em três camadas, convenientemente adensadas. Após desmoldada a argamassa é submetida a um esforço dinâmico, impelido por uma sequência de 30 golpes desferidos em um período de 30 s. A média de duas medidas de diâmetros ortogonais, em milímetros, da argamassa deformada após a ação mecânica descrita, define o índice de consistência [11]. Para este trabalho foi definido uma consistência de $170 \mathrm{~mm}( \pm 20 \mathrm{~mm})$, pois a mesma foi ideal para o lançamento e adensamento das argamassas geopoliméricas nos moldes metálicos.

\section{RESULTADOS E DISCUSSÃO}

$\mathrm{Na}$ Tabela II são apresentadas as composições das argamassas geopoliméricas e a relação água/materiais secos (cinza volante/metacaulim) necessária para que cada argamassa apresentasse consistência de $170 \mathrm{~mm} \pm 20 \mathrm{~mm}$.

Observou-se que à medida que o teor de $\mathrm{AF}$ foi aumentado na mistura, em substituição a areia de construção, fez-se necessário adicionar maior quantidade de água para manter a mesma consistência. Segundo Armange et al. [11], que utilizou AF em argamassas à base de cimento Portland, a maior quantidade de água para argamassas contendo maiores teores de $\mathrm{AF}$ se deve à hidratação da argila presente no resíduo. Além de absorver água, a argila diminui a trabalhabilidade da argamassa. Comportamento semelhante foi observado em concretos contendo AF [12]. Os autores verificaram que para a mesma consistência do concreto (teste de slump) foi necessária maior quantidade de aditivo superplastificante nos concretos contendo $\mathrm{AF}$ em relação aos concretos isentos do resíduo.

Na Fig. 3 são apresentados os resultados médios de resistência à compressão das argamassas geopoliméricas nas idades de 7 e 28 dias.

Como pode ser observado na Fig. 3, a adição de AF influenciou na resistência à compressão das argamassas geopoliméricas. Quanto maior a quantidade de $\mathrm{AF}$ em substituição à areia de construção, maior foi a redução da resistência. Isto está relacionado ao aumento da quantidade de água na argamassa para manter a consistência entre o intervalo definido neste trabalho $(170 \mathrm{~mm} \pm 20 \mathrm{~mm})$. Este comportamento foi constatado também por [13] em argamassas de cimento Portland. Os autores verificaram que

Tabela II - Relação água/materiais secos (cinza volante/metacaulim) para as argamassas geopoliméricas com índice de consistência de $170 \mathrm{~mm}( \pm 20 \mathrm{~mm})$.

[Table II - Relationship water/dry materials (fly ash/metakaolin) for geopolymeric mortars with consistency index of $170 \mathrm{~mm}( \pm 20 \mathrm{~mm})$.]

\begin{tabular}{cccccc}
\hline $\begin{array}{c}\text { Teor de areia } \\
\text { de fundição }\end{array}$ & $\begin{array}{c}\text { Concentração } \\
\text { Cinza Volante }\end{array}$ & $\begin{array}{c}\text { Concentração } \\
\text { Metacaulim }\end{array}$ & $\begin{array}{c}\text { Concentração } \\
\text { Silicato de Sódio* }\end{array}$ & $\begin{array}{c}\text { Concentração } \\
\text { Hidróxido de Sódio* }\end{array}$ & $\begin{array}{c}\text { Relação água/ } \\
\text { CV+MK }\end{array}$ \\
\hline $0 \%$ & & & & & 0,50 \\
$25 \%$ & & & & & 0,71 \\
$50 \%$ & & & & $21 \%$ & 0,80 \\
$75 \%$ & $30 \%$ & & & & 1,04 \\
$100 \%$ & & & & 1,06 \\
\hline
\end{tabular}

*Em relação à quantidade total de cinza volante e metacaulim. 
as argamassas apresentaram queda progressiva na resistência à compressão para concentrações de resíduo superiores a $20 \%$.

Observa-se que houve queda acentuada na resistência à compressão das argamassas contendo $25 \%$ de AF em relação às amostras isentas do resíduo. Isto corrobora com os resultados de [13] indicando que teores ideais de substituição de areia de construção por AF devam estar em menos de $20 \%$ quando o objetivo seja boa relação entre teor de substituição de $\mathrm{AF} /$ resistência à compressão.

Na Fig. 4 são apresentados os difratogramas de raios $X$ da $\mathrm{CV}$, do $\mathrm{MK}$, da AF e das argamassas geopoliméricas com idade de 28 dias.

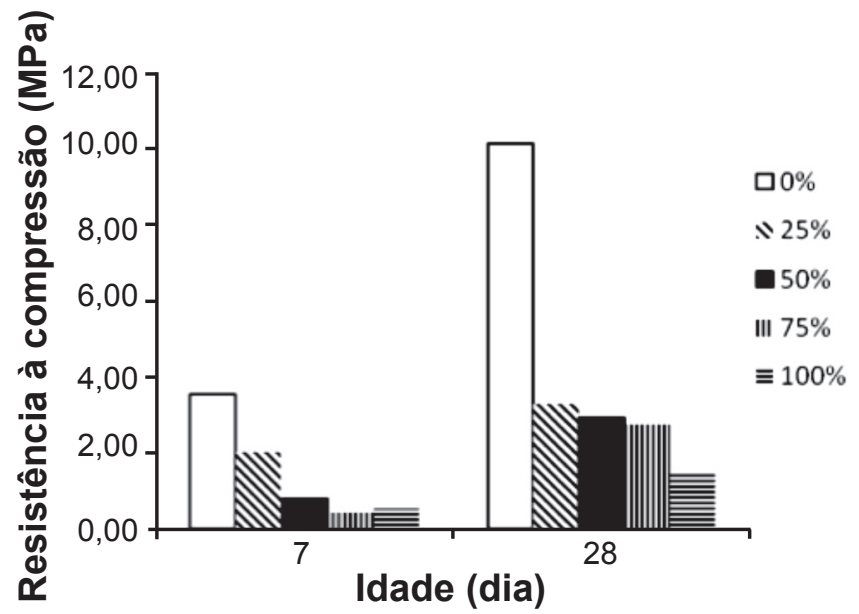

Figura 3: Resistência à compressão das argamassas geopoliméricas com e sem adição de areia de fundição (MPa).

[Figure 3: Compressive strength of geopolymeric mortars with and without addition of sand of casting (MPa).]

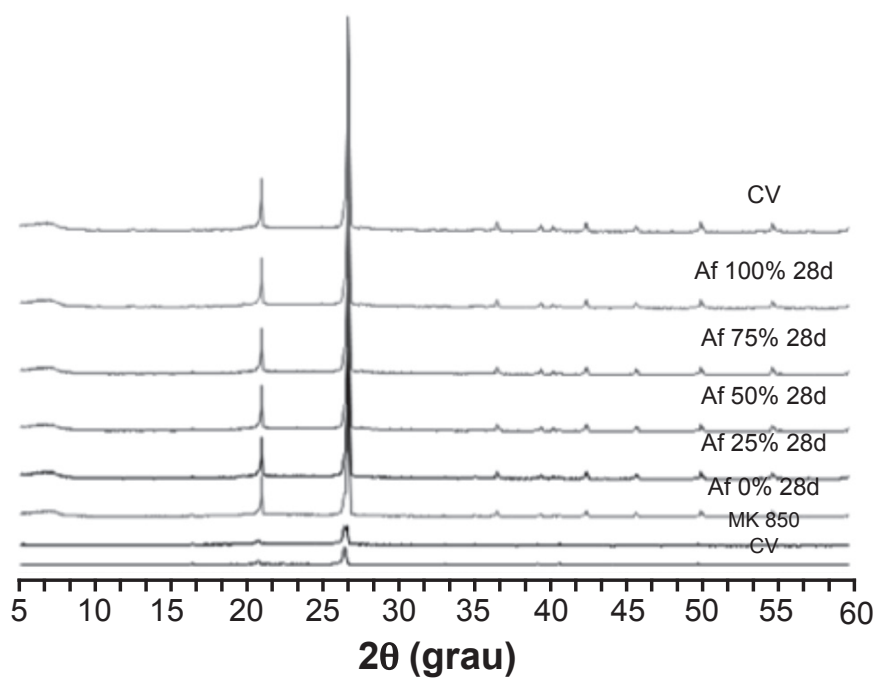

Figura 4: Difratogramas de raios X da cinza volante, metacaulin, areia de fundição e das argamassas geopoliméricas com e sem adição de $\mathrm{AF}$ aos 28 dias.

[Figure 4: X-ray diffraction patterns fly ash, metakaolin, foundry sand mortar and geopolymeric mortars with and without addition of AF 28 days.] (a)

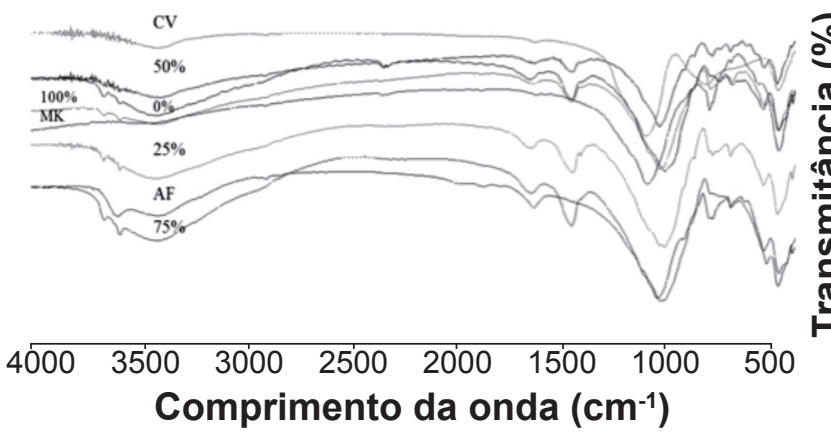

(b)

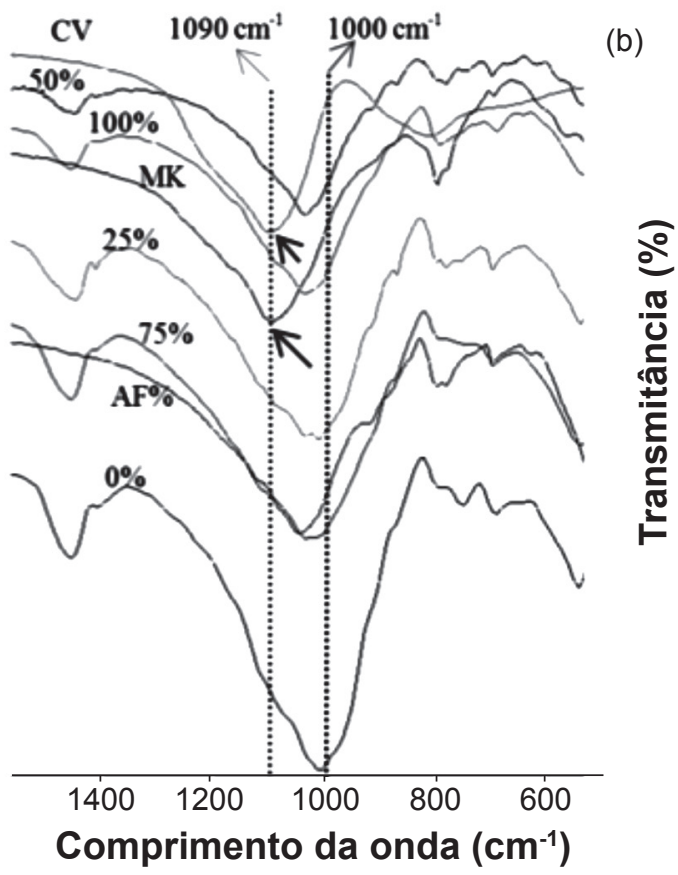

Figura 5: Espectros de FTIR - (1) 4000-400 cm $\mathrm{cm}^{-1}$; (2) $1600-600 \mathrm{~cm}^{-1}$ : $\mathrm{CV}, \mathrm{MK}, \mathrm{AF}$ e argamassas (idade de 28 dias) contendo $0 \%, 25,50 \%$, $75 \%$ e $100 \%$ de AF.

[Figure 5: FTIR spectra of - (1) 4000-400 cm-1 ; (2) 1600-600 $\mathrm{cm}^{-1}$ : $C V, M K, A F$ and mortars (28 days old) containing 0\%, 25, 50\%, $75 \%$ and $100 \%$ AF.]

Quando são observados os espectros das matériasprimas utilizadas no processo $(\mathrm{CV}, \mathrm{MK}$ e $\mathrm{AF})$ não são identificados novos picos cristalinos nas argamassas geopoliméricas, independente do traço utilizado. Este comportamento é distinto do verificado nos trabalhos de [7, 14-17], que identificaram picos cristalinos de zeólitas e compostos carbonatados como natrita $\left(\mathrm{Na}_{2} \mathrm{CO}_{3}\right)$ e trona $\left(\mathrm{Na}_{3} \mathrm{H}\left(\mathrm{CO}_{3}\right)_{2} \cdot 2 \mathrm{H}_{2} \mathrm{O}\right)$. Estes compostos são formados a partir da carbonatação do sódio livre na matriz geopolimérica, sódio este presente nos ativadores alcalinos. É importante salientar que havendo baixos teores de compostos cristalinos (> 4\%) na matriz cimentante, estes não são detectados no difratogramas de raios X. Portanto, apenas com base do difratogramas de raios $\mathrm{X}$ conclui-se que a areia de fundição minimizou a formação destes compostos cristalinos na 
matriz geopolimérica, uma vez que não foram identificados nos difratogramas mostrados na Fig. 4.

Na Fig. 5 são apresentados os espectros de FTIR da CV, do MK, da AF e das argamassas geopoliméricas com idade de 28 dias. Na Fig. 5 (1) são apresentados os espectros com comprimento de onda entre 4000 e $400 \mathrm{~cm}^{-1}$. Na Fig. 5 (2) são apresentados os espectros entre os intervalos de $1600 \mathrm{e}$ $400 \mathrm{~cm}^{-1}$, possibilitando assim uma análise mais elaborada das amostras.

Com base nos espectros de FTIR da CV e do MK, apresentados na Fig. 5, observa-se que bandas características destes materiais estão por volta de $1090 \mathrm{~cm}^{-1}$. Bandas nesta região estão relacionadas a vibrações de $\mathrm{Si}-\mathrm{O}$ e vibrações de Al-O. Estas bandas estão bem definidas nas matérias-primas utilizadas como precursores geopoliméricos. Para Bakharev (2005), os modos de estiramento são sensíveis à composição $\mathrm{Si}-\mathrm{Al}$ das redes e podem mudar para baixas frequências com o aumento do número de átomos de alumínio tetraédrico [18].

Os geopolímeros possuem estrutura à base de Si-O-Al-O, cuja banda característica no espectro de FTIR esta próxima a $1000 \mathrm{~cm}^{-1}$. Bandas nesta região estão relacionadas aos estiramentos assimétricos de $\mathrm{Al}-\mathrm{O}-\mathrm{Si}$, característicos da policondensação dos aluminossilicatos no processo de álcali-ativação. É por esta razão que ocorre um deslocamento da banda 1090 $\mathrm{cm}^{-1}$ (CV e MK) para bandas de menor frequência para as amostras álcali-ativadas $\left(\sim 1000 \mathrm{~cm}^{-1}\right)$. Conforme Van Jaarsveld et al. (1997) é importante que o meio esteja fortemente alcalino para dissolver a sílica e alumínio, bem como hidrolisar a superfície das matérias-primas, para gerar a policondensação dos aluminossilicatos, de modo que quanto melhor for o processo de policondesação dos aluminossilicatos, mais definida é a banda [19]. Observando o espectro da amostra contendo $0 \%$ de AF observa-se que a banda próxima de $1000 \mathrm{~cm}^{-1}$ está bem definida mostrando que o processo de policondensação dos aluminossilicatos ocorreu de forma eficiente, o que reflete resistências mais altas para estas amostras na idade de 28 dias (10 MPa). Quando são observados os espectros das argamassas contendo a AF nesta região, os espectros apresentam uma base mais alargada na região do espectro (um vale mais alargado) quando comparado ao espectro da amostra $0 \%$ (um vale com forma mais estreita). Isto indica que o processo de policondensação dos aluminossilicatos foi prejudicado pela AF, conduzindo a menor formação de uma estrutura Si-O-Al-O, o que explica o menor desempenho da resistência à compressão em relação às argamassas isentadas do resíduo. Bandas próximas a $3450 \mathrm{~cm}^{-1}$ e a $1650 \mathrm{~cm}^{-1}$ indicam a presença de moléculas de água, ou seja, essas bandas seriam provenientes de água adsorvida da atmosfera pela cinza volante (CV), metacaulim (MK) e areia de fundição (AF). A banda próxima a $3450 \mathrm{~cm}^{-1}$ está relacionada a vibrações de estiramento simétrico e assimétrico das moléculas de H-O-H, enquanto que a banda em torno de $1650 \mathrm{~cm}^{-1}$ está relacionada com deformações angulares das ligações H-O-H. Bandas próximas a $796 \mathrm{~cm}^{-1} \mathrm{e}$ a $693 \mathrm{~cm}^{-1}$ estão relacionadas à presença de alumínio e quartzo, respectivamente, fazendo parte da composição química da $\mathrm{CV}$ e do MK. A banda próxima a $800 \mathrm{~cm}^{-1}$ está relacionada às vibrações de $\mathrm{AlO}_{4}$, enquanto que a banda próxima a 688 $\mathrm{cm}^{-1}$ está relacionada às vibrações simétricas de estiramento do $\mathrm{Si}-\mathrm{O}-\mathrm{Si}$, em amostras de CV. As bandas 560 e 460 $\mathrm{cm}^{-1}$ também foram identificados nas amostras de CV antes e depois do álcali-ativação. Esses resultados são semelhantes aos obtidos por Palomo [9], que identificaram as bandas em CV antes e depois da álcali-ativação. Para estes autores, a banda $560 \mathrm{~cm}^{-1}$ é característica da presença de mulita, já regiões próximas a $460 \mathrm{~cm}-1$ são atribuídas a deformações angulares dos tetraedros $\mathrm{SiO}_{4}(\mathrm{O}-\mathrm{Si}-\mathrm{O})$, provavelmente relacionados ao quartzo. É importante salientar que a mulita, composto cristalino identificado no espectro de DRX da cinza volante (Fig. 2), esta presente nas argamassas álcali-ativadas o que mostra que este composto permanece nas argamassas, mesmo quando submetido a um ambiente fortemente alcalino. Da mesma forma o quartzo, que está presente tanto no MK quanto na $\mathrm{CV}$, conforme identificado nos difratogramas de raios X (Fig. 2). As bandas características de quartzo $784 \mathrm{e}$ $690 \mathrm{~cm}^{-1}$ são vistas nos espectros. A banda de carbonato, que ocorre em entre 1460 e $1440 \mathrm{~cm}^{-1}$, aparece nos espectros das amostras álcali-ativadas, indicando que o carbonato de sódio está presente. Isto ocorreu devido à presença de $\mathrm{Na}+$ livres que reagiram com o $\mathrm{CO}_{2}$ da atmosfera. Portanto, houve a formação de compostos carbonatados nas argamassas com e sem a presença de $\mathrm{AF}$, apesar destes compostos não terem sido identificados nos espectros de DRX devido à baixa concentração destes compostos.

\section{CONCLUSÃO}

O aumento do teor de substituição da areia da construção civil pela areia de fundição influenciou negativamente no desempenho mecânico das amostras álcali-ativadas, verificado por meio de ensaios de resistência à compressão. Isto está relacionado à maior quantidade de água que foi necessária utilizar, na medida em que o teor de AF nas argamassas foi aumentado, para manter o índice de consistência estabelecido $(170 \pm 20 \mathrm{~mm})$. As argamassas contendo $25 \%$ de AF atingiram a resistência à compressão de 3,30 $\mathrm{MPa}$ na idade de 28 dias. Este foi o melhor resultado para as argamassas contendo o resíduo, o que mostra que percentagens menores de AF deverão ser estudadas para determinar um teor ideal para que o desempenho mecânico das amostras contendo $\mathrm{AF}$ não seja tão inferior quando comparado às amostras isentas deste tipo de resíduo. Os difratogramas de raios $\mathrm{X}$ das amostras geopoliméricas na idade de 28 dias apresentaram apenas picos característicos de quartzo. Entretanto, foram identificadas bandas características de compostos carbonatados nos espectros de FTIR de todas as argamassas, independente do teor de AF. Ou seja, a concentração de compostos carbonatados foi baixa pois não foram identificados por difração de raios X. Nos espectros de FTIR foi verificado que a areia de fundição interferiu no processo de policondensação dos aluminossilicatos, o que justifica a baixa resistência das argamassas contendo o resíduo, pois a banda característica dos geopolímeros em $1000 \mathrm{~cm}^{-1}$ se apresentou mais alargada quando comparada à banda das argamassas isentas do resíduo. 


\section{AGRADECIMENTOS}

À FAPERGS, ao CNPq e à Central Analítica da Universidade Feevale.

\section{REFERÊNCIAS}

[1] V. Chiaverini, Tecnologia Mecânica, Makron Books do Brasil Editora Ltda. (1986).

[2] W. Callister Jr., Ciência e Engenharia dos Materiais: uma introdução, Editora LTC (2011).

[3] A. G. Soares, Fundição: Mercado, Processos e Metalurgia, $1^{\text {a }}$ Ed., COPPE/UFRJ (2000).

[4] ABIFA - Associação Brasileira de Fundição - Comissão de Meio Ambiente, "Manual de regeneração e reuso de areias de fundição", Associação Brasileira de Fundição, S. Paulo, SP (1999) 1-49.

[5] G. Schmitz, "Estudo da Viabilidade Técnica da Adição de Areia de Fundição em Matrizes Geopolimericas", Trabalho de Conclusão de Curso de Eng. Ind. Química, Univ. Feevale (2011).

[6] D. M. Roy, "Alkali-activated cements opportunities and challenges", Cem. Concr. Res. 29 (2005) 249-254.

[7] A. S. Vargas, D. Dal Molin, A. Vilela, F. Silva, B. Pavão, H. Veit, "The effects of $\mathrm{Na}_{2} \mathrm{O} / \mathrm{SiO}_{2}$ molar ratio, curing temperature and age on compressive strength, morphology and microstructure of alkali-activated fly ash-based geopolymers", Cem. Concr. Composites 33, 6 (2011) 653660.

[8] F. Puertas, A. F. Juménez, "Mineralogical and microstructural characterisation of alkali-activated ash/slag pastes", Cem. Concr. Composites 25 (2003) 287-292.

[9] A. Palomo, M. W. Grutzeck, M. T. Blanco, "Alkaliactivated fly ashes. A cement for the future", Cem. Concr. Res. 29 (1999) 1323-1329.

[10] American Society for Testing and Materials (ASTM),
Standard practice for use of apparatus for determination of length change of hardened cement paste, mortar, and concrete, Annual Book of ASTM Standards, Philadelphia C 490 (1997).

[11] NBR 13276, "Argamassa para assentamento e revestimento de paredes e tetos - Preparo da mistura e determinação do índice de consistência", Rio de Janeiro, RJ (2005).

[12] R. Siddique, G. Schutter, A. Noumowe, "Effect of usedfoundry sand on the mechanical properties of concrete", Construction Building Mater. 23 (2009) 976-980.

[13] L. C. Armange, "Utilização de areia de fundição residual para uso em argamassas", Rev. Matéria 10, 1 (2005) 51-62. [14] G. Kovalchuk, A. Fernandez-Jimenez, A. Palomo, "Alkali-activated fly ash: Effect of thermal curing conditions on mechanical and microstructural development - Part II", Fuel 86 (2007) 315-322.

[15] M. Criado, A. Fernandez-Jimenez, A. G. Torre, M. A. G Aranda, A. Palomo, "An XRD study of the effect of the $\mathrm{SiO}_{21}$ $\mathrm{Na}_{2} \mathrm{O}$ ratio on the alkali activation of fly ash", Cem. Concr. Res. 37, 5 (2007) 671-679.

[16] M. Criado, A. Fernandez-Jimenez, A. Palomo, "Alkali activation of fly ash: Effect of the $\mathrm{SiO}_{2} / \mathrm{Na}_{2} \mathrm{O}$ ratio: Part I: FTIR study", Microporous Mesoporous Mater. 106, 1-3 (2007) 180-191.

[17] A. Fernandez-Jimenez, M. Monzó, M. Vicent, A. Barba, A. Palomo, "Alkaline activation of metakaolin-fly ash mixtures: Obtain of Zeoceramics and Zeocements", Microporous Mesoporous Mater. 108, 1-3 (2008) 41-49.

[18] T. Bakharev, "Durability of geopolymer materials in sodium and magnesium sulfate solutions", Cem. Concr. Res. 35 (2005) 1233-1246.

[19] J. G. S. Van Jaarsveld, J. S. J. Van Deventer, L. Lorenzen, "The potential use of geopolymeric materials to immobilise toxic metals: part I. Theory and applications", Minerals Eng. 10, 7 (1997) 659-669.

(Rec. 26/08/2013, Rev. 10/11/2014, Ac. 08/05/2015) 